\title{
In vitro and in vivo bioactivity of recombinant canine hepatocyte growth factor
}

\author{
Brigitte Arends ${ }^{\mathrm{a}, *}$, Bart Spee ${ }^{\mathrm{a}, \mathrm{e}}$, Gaby Hoffmann ${ }^{\mathrm{a}}$, Georgina E.G. Jansen ${ }^{\mathrm{a}}$, Estel Slump ${ }^{\mathrm{a}}$, \\ Edoardo Auriemma ${ }^{\mathrm{a}}$, Jooske IJzer ${ }^{\mathrm{b}}$, Wieger Hemrika ${ }^{\mathrm{c}}$, Roland A. Romijn ${ }^{\mathrm{c}}$, \\ Karin H.A. van der Heijden-Liefkens ${ }^{\mathrm{d}}$, Paul J.A. Sondermeijer ${ }^{\mathrm{d}}$, \\ Ted S.G.A.M. van den Ingh ${ }^{a}$, Louis C. Penning ${ }^{a}$, Jan Rothuizen ${ }^{a}$ \\ ${ }^{\text {a }}$ Faculty of Veterinary Medicine, Department of Clinical Sciences of Companion Animals, Utrecht University, \\ Yalelaan 104, 3584 CM Utrecht, the Netherlands \\ ${ }^{\mathrm{b}}$ Faculty of Veterinary Medicine, Department of Pathobiology, Utrecht University, Yalelaan 1, 3584 CL Utrecht, the Netherlands \\ ${ }^{c}$ ABC Protein Expression Centre, Utrecht University, Padualaan 8, 3584 CH Utrecht, the Netherlands \\ d Intervet International, Wim de Körverstraat 35, 5830 AA Boxmeer, the Netherlands \\ e Department of Molecular Pathology, University Hospitals of Leuven, Minderbroederstraat 12, 3000 Leuven, Belgium
}

Accepted 8 November 2007

\begin{abstract}
Hepatocyte growth factor (HGF) is crucial for the development and regeneration of the liver and offers a possible new therapeutic strategy for the treatment of canine liver disease. In this study, the in vitro and in vivo bioactivity of recombinant canine HGF (rcHGF) produced with a baculoviral expression system in insect cells was measured.

In vitro rcHGF induced mitogenesis, motogenesis, and phosphorylated the HGF receptor c-MET and its downstream mediators PKB and ERK1/2 in two canine epithelial cell lines. After a partial hepatectomy (phx) in dogs, rcHGF increased phosphorylation of c-MET, PKB and ERK1/2. A moderate increase was seen with the cell cycle protein PCNA in rcHGF treated livers, but no HGF-induced increase in liver weight was seen 7 days after phx. Furthermore, rcHGF treated livers showed lower levels of the key mediator of apoptosis, caspase-3, at 7 days after phx. It is concluded that rcHGF is a biologically active protein in vitro and in vivo and the baculoviral expression system supplies sufficient amounts of rcHGF for future clinical studies in dogs.
\end{abstract}

(c) 2007 Elsevier Ltd. All rights reserved.

Keywords: HGF; c-MET; PKB; ERK1/2; PCNA; Partial hepatectomy; Liver regeneration; Dogs

\section{Introduction}

Hepatocyte growth factor (HGF) is a multifunctional heterodimeric glycoprotein, synthesised and secreted by cells of mesenchymal origin and targeting epithelial and endothelial cells in an endocrine and/or paracrine fashion (Matsumoto and Nakamura, 1992). The biological activities of HGF are triggered by the phosphorylation of tyro-

\footnotetext{
* Corresponding author. Tel.: +31 30253 3943; fax: +31 302518126.

E-mail address: B.Arends@vet.uu.nl (B. Arends).
}

sine residues of a heterodimeric membrane-spanning tyrosine kinase receptor that is encoded by the proto-oncogene c-MET (Bottaro et al., 1991; Ma et al., 2003). Activation of the c-MET signalling pathway induces a number of cellular responses, including mitogenic, motogenic, morphogenic, and anti-apoptotic activities (Maulik et al., 2002; Stella and Comoglio, 1999). These activities play an important role in embryological development and regeneration of many tissues such as the liver (Borowiak et al., 2004; Schmidt et al., 1995), kidneys (Liu, 2004), heart (Jin et al., 2004), and neural tissues (Maina and Klein, 1999). 
Serum levels of HGF are increased in many liver diseases (Funakoshi and Nakamura, 2003; Shiota et al., 1995). Furthermore, exogenous administration of recombinant HGF or induction of an increased expression of the HGF gene has been found to be protective, even lifesaving in toxin-induced fulminating and chronic liver failure in rodent models (Kosai et al., 1999; Matsuda et al., 1997; Ueki et al., 1999; Yasuda et al., 1996). Therefore, HGF is considered the most important factor for growth and regeneration of the liver and may be a potential therapeutic agent for the treatment of liver diseases in which growth or regeneration is hampered.

The overall incidence of liver disease in dogs has been estimated at around 1-2\% of clinical cases (Rothuizen, 1999; Rothuizen and Meyer, 2000). In hepatic under-development, such as congenital portosystemic shunt and primary portal vein hypoplasia, and liver diseases in which regeneration is hampered, such as in chronic inflammation and cirrhosis, HGF or c-MET pathways are altered (Spee et al., 2006; Spee et al., 2005). These altered regeneration pathways provide a rationale for the therapeutic use of HGF. However, no therapeutic evaluation of HGF has been performed in dogs, possibly reflecting the high cost and the lack of sufficient quantities of ready available recombinant $\mathrm{HGF}$ (rcHGF).

In the present study, rcHGF was produced using a baculoviral expression system in insect cells (Kost et al., 2005). The bioactivity of rcHGF was measured in vitro using two canine epithelial cell lines. The effect of rcHGF on the activation of c-MET and downstream pathways was measured in dogs that had received a 30\% partial hepatectomy (phx). The phx model is a widely used technique to study liver regeneration in vivo. After phx, the remaining hepatocytes enter the G1 phase of the cell cycle, which makes the normally quiescent hepatocytes more responsive towards growth factors such as HGF (Webber et al., 1994). These results provide the basis for future application of rcHGF in naturally occurring canine liver diseases.

\section{Materials and methods}

\section{Cell lines and cultures}

Canine bile duct epithelial (BDE) cells were acquired from the Amsterdam Medical Centre Experimental Liver Cell Bank (Oda et al., 1991). BDE cells have a hepatocyte-like differentiation profile because they express albumin and ceruloplasmin, as determined by quantitative polymerase chain reaction (Q-PCR) and immunodetection. MadinDarby canine kidney (MDCK) cells were purchased from the American Type Culture Collection. Both cultures were maintained in Dulbecco's modified Eagle's medium (DMEM; Invitrogen) supplemented with 10\% fetal calf serum (FCS, PAA Laboratories) and standard antibiotics at $37{ }^{\circ} \mathrm{C}$ with $5 \% \mathrm{CO}_{2}$ and $95 \%$ air in a humidified atmosphere. High-5 cells were cultured in SF900 medium (Invitrogen) containing 3\% FCS.

\section{Expression and purification $\mathrm{rcHGF}$}

The rcHGF was produced by infecting High- 5 cells with recombinant baculovirus (Invitrogen) expressing the complete coding region of canine
HGF (Miyake et al., 2003). Three days after infection, rcHGF-containing supernatant was harvested and concentrated by ultra microfiltration (NORIT Membrane Technology). The concentrate was centrifuged at $100,000 \mathrm{~g}$ for $1 \mathrm{~h}$ to remove the baculovirus particles, and gamma irradiated ( $25 \mathrm{kGray})$ to inactivate residual baculovirus.

The rcHGF was purified using a heparin-sepharose CL-6B column (Amersham Biosciences). After loading and washing the column according to the manufacturer's instructions, rcHGF was eluted with a linearly increasing gradient of $0.4-1.5 \mathrm{mM} \mathrm{NaCl}$ in $25 \mathrm{mM}$ Tris- $\mathrm{HCl}$. Elution samples $(0.5 \mathrm{~mL})$ were collected for further protein determination. To show the presence of rcHGF in different elution samples, Western blotting was performed with a specific HGF antibody (Table 1). The degree of rcHGF purification was estimated using densitometry analysis (QuantityOne software, Geldoc2000 system) of a silver stained Tris- $\mathrm{HCl}$ polyacrylamide gel. The rcHGF concentration was measured in an ELISA based on capturing with a mouse monoclonal antibody against human HGF (Lab Vision Corporation) and detection with a biotin labelled, goat polyclonal antibody against human HGF (Lab Vision Corporation). The results from the ELISA and the bioactivities of rcHGF were validated towards a standard line of recombinant human HGF (rhHGF; R\&D systems) with known concentrations.

\section{In vitro biological activity}

The mitogenic in vitro activity of rcHGF was measured using the colorimetric 3-[4,5-dimethylthiazol-2-yl]-2,5-diphenyltetrazolium bromide (MTT) proliferation assay (Carmichael et al., 1987). Cells were seeded in each well of a 96-well culture plate at a density of $1.5 \times 10^{3}$ cells per well in DMEM medium containing 1\% FCS. After an overnight culture starvation period, rcHGF or rhHGF was added in the first three wells to a final concentration of $300 \mathrm{ng} / \mathrm{mL}$. The HGF containing medium was serially diluted threefold at each step, except for the last column (control cells). After $24 \mathrm{~h}$ under culture conditions, $0.5 \mathrm{mg} / \mathrm{mL}$ MTT (Sigma) were added to each well for $3 \mathrm{~h}$. Cell growth was calculated as percentage increase in absorbance of treated cells compared to non-treated cells. MTT assay data are represented as mean values \pm standard deviation $(\mathrm{SD})$ of two independent experiments performed in triplicate.

The motogenic in vitro activity of rcHGF on BDE and MDCK cells was evaluated by HGF-induced cell scattering (Stoker and Perryman, 1985). Cells were seeded in 8-well chamber slides (Labtek II) in a concentration of $3 \times 10^{3}$ cells per well in DMEM with $1 \%$ FCS in the presence of 0,10 , or $100 \mathrm{ng}$ reHGF or rhHGF per millilitre. The experiment was performed in triplicate. After a 10-h culture period, cells were fixed in Boonfix (Finetec) for $5 \mathrm{~min}$ and stained with haematoxylin for $1 \mathrm{~min}$. Photomicrographs were taken from cells of the respective wells at $20 \times$ magnification.

Activation of the HGF receptor c-MET and the downstream mediators PKB and ERK1/2 were shown in BDE and MDCK cells by Western blotting. Cells were seeded in 6-well tissue culture plates at a density of $1.5 \times 10^{5}$ cells per well in DMEM supplemented with $1 \%$ FCS. After an overnight starvation period, cells were treated with $0,1.5,15$, or $150 \mathrm{ng} /$ $\mathrm{mL} \mathrm{rcHGF}$ for $5 \mathrm{~min}$. Protein isolation and Western blotting were performed as described below.

\section{In vivo biological activity}

The animal experiment was approved by and performed according to the standards of the Ethics Committee of Animal Experimentation of the Utrecht University.

To study biological activity in vivo, 12 female beagle dogs (Harlan Winkelmann), $10-12$ months old and weighing $8.5-11 \mathrm{~kg}$, were used. Before surgery, the dogs were premedicated with $0.03 \mathrm{mg} / \mathrm{kg}$ acepromazine (Vetranquil, CEVA Santé Animale), $0.5 \mathrm{mg} / \mathrm{kg}$ methadone (Methadon $\mathrm{HCl}$, Eurovet Animal Health) and $0.02 \mathrm{mg} / \mathrm{kg}$ atropine (Atropinesulfaat, Pharmachemie). Anaesthesia was induced with $5 \mathrm{mg} / \mathrm{kg}$ propofol (Propovet, Abbott) and maintained with inhalation anaesthesia with nitrous oxide, oxygen, and isoflurane (IsoFlo, Abbott). Additional 
Table 1

Antibodies used in Western blot experiments

\begin{tabular}{|c|c|c|c|c|c|}
\hline Antigen & Manufacturer & Product size & Dilution & Secondary antibody & Dilution \\
\hline HGF & Lab Vision (clone 4c12.1) & 82 & $1: 100$ & Anti-mouse & $1: 20,000$ \\
\hline c-MET & Sigma (H97861) & 169 & $1: 750$ & Anti-goat & $1: 20,000$ \\
\hline p-c-MET ${ }^{\mathrm{a}}$ & Abcam (Ab5662) & 169 & $1: 750$ & Anti-rabbit & $1: 20,000$ \\
\hline PKB & BD Bioscience (610876) & 58 & $1: 250$ & Anti-mouse & $1: 20,000$ \\
\hline p-PKB ${ }^{b}$ & Cell Signaling (9275) & 58 & $1: 1000$ & Anti-rabbit & $1: 20,000$ \\
\hline ERK $1 / 2$ & Cell Signaling (9102) & $44 / 42$ & $1: 1000$ & Anti-rabbit & $1: 20,000$ \\
\hline $\mathrm{p}-\mathrm{ERK} 1 / 2^{\mathrm{c}}$ & Cell Signaling (9101) & $44 / 42$ & $1: 1500$ & Anti-rabbit & $1: 20,000$ \\
\hline PCNA & DAKO (M0879) & 36 & $1: 1000$ & Anti-mouse & $1: 20,000$ \\
\hline Caspase-3 & Calbiochem (235412) & $34 / 20 / 18$ & $1: 500$ & Anti-rabbit & $1: 40,000$ \\
\hline Beta-actin & Lab Vision (pan Ab-5) & 40 & $1: 2000$ & Anti-mouse & $1: 20,000$ \\
\hline
\end{tabular}

${ }^{a}$ Phospho Y1230, Y1234, Y1235.

b Phospho T308.

${ }^{\mathrm{c}}$ Phospho T202, Y204.

intraoperative analgesia was provided by an initial dose of $15 \mu \mathrm{g} / \mathrm{kg}$ sufentanil (Sufenta forte, Janssen Cilag) at time of incision and thereafter the same dose was given every $30 \mathrm{~min}$. Postoperative analgesia was provided with repeated intramuscular injections of $18 \mu \mathrm{g} / \mathrm{kg}$ buprenorphine (Temgesic, Schering-Plough) every $8 \mathrm{~h}$ over a period of at least 3 days.

Phx was performed by excision of the left lateral lobe by using a Cavitron Ultrasonic Surgical Aspirator. To permit injections of rcHGF or $\mathrm{NaCl}$ directly into the portal vein, the superior mesenteric vein was cannulated with a catheter (UNO Roestvaststaal). Directly after phx and thereafter every $24 \mathrm{~h}$ for 7 days, $10 \mu \mathrm{g} / \mathrm{kg}$ rcHGF (dissolved in $0.2 \mathrm{M}$ $\mathrm{NaCl}$ ) was injected into the catheter. The dose of $10 \mu \mathrm{g} / \mathrm{kg}$ was based on the literature reports of several rodent studies and one dog study (Ido et al., 2004; Ishiki et al., 1992; Kobayashi et al., 1996; Webber et al., 1994). Prior to HGF injection, ultrasound guided liver biopsies were taken with a $14 \mathrm{G}$ true cut needle (Medical device technologies) under local anaesthesia with $2 \mathrm{~mL}$ of $2 \%$ xylocaine plus $5 \%$ adrenaline at $2,3,4$, and 5 days following phx.

Seven days after phx, the dogs were euthanased using an overdose of pentobarbital via the cephalic vein. Weights of the liver, kidneys, heart, and spleen were measured and organ weight/bodyweight ratios were calculated. Significant differences in organ weight were analysed with a Student's $t$ test by using SPSS software (SPSS Benelux). A $P$ value $<0.05$ was considered statistically significant. Normal distribution was measured by the Kolmogorov-Smirnov test.

Formalin-fixed biopsies from the liver were embedded in paraffin, sliced, and stained with haematoxylin and eosin (H\&E). The slides were examined by a certified veterinary pathologist.

\section{Protein electrophoresis, silver staining, and Western blotting}

Proteins were obtained by homogenising cells or liver biopsies in radioimmunoprecipitation assay (RIPA) buffer containing 1\% Igepal, $0.6 \mathrm{mM}$ phenylmethylsulfonyl-fluoride, $17 \mu \mathrm{g} / \mathrm{mL}$ aprotinine, and $1 \mathrm{mM}$ sodiumorthovanadate (Sigma). Twenty micrograms of pooled protein extracts were electrophoresed on Tris- $\mathrm{HCl}$ polyacrylamide gels (Biorad), using a Mini Trans-Blot Cell blot-apparatus (Biorad). To detect the total amount of proteins, gels were stained with a Biorad Silver Stain kit, according to the manufacturer's instructions. For Western blotting, proteins were transferred to Hybond-C Extra nitrocellulose membranes (Amersham Biosciences Europe). The procedure for immunodetection was based on an ECL Western blot analysis system (Amersham Biosciences Europe). Antibodies and used dilutions are described in Table 1. Densitometric quantification was performed in triplicate with a Geldoc2000 system with QuantityOne 4.3.0 software (Biorad).

Differences in the optical densities (OD) of the Western blot immunoreactive bands were analysed with a Mann-Whitney $U$ test using SPSS software. A $P$ value $<0.05$ was considered statistically significant.

\section{Immunohistochemistry}

Immunohistochemistry was performed on Proliferating Cell Nuclear Antigen (PCNA; DAKO), a cell-cycle dependent protein that is synthesised in early G1 and S phases of the cell cycle. Formaldehyde (4\%) fixated, paraffin imbedded sections were mounted on poly-L-lysine coated slides, post-fixed in ice-cold acetone for $10 \mathrm{~min}$, air dried and stored at $4{ }^{\circ} \mathrm{C}$ until use.

For antigen retrieval, slides were boiled in $10 \mathrm{mM}$ citrate buffer $(\mathrm{pH}$ 6.0 ) in a microwave oven for $20 \mathrm{~min}$. Endogenous peroxidase activity was blocked by $0.3 \% \mathrm{H}_{2} \mathrm{O}_{2}$ in methanol for $30 \mathrm{~min}$. Background staining was blocked by incubating the sections with normal goat serum 1:10 diluted in Tris-buffered saline (TBS; $0.01 \mathrm{M}$ Tris, $0.9 \% \mathrm{NaCl}, 0.1 \%$ Tween-20, $\mathrm{pH}=7.6$ ) for $30 \mathrm{~min}$. Sections were incubated overnight at $4{ }^{\circ} \mathrm{C}$ with the primary antibody PCNA (1:5,000 in TBS). Sections were incubated in goat anti-mouse IgG (EnVision, DAKO) for $45 \mathrm{~min}$ at room temperature. The peroxidase activity was visualised by applying $0.5 \mathrm{mg} / \mathrm{mL} 3,3$-diaminobenzidine chromogen containing $0.035 \%$ hydrogen peroxide in PBS, for $10 \mathrm{~min}$ at room temperature. Sections were counterstained with haematoxylin for $1 \mathrm{~min}$.

The average numbers of PCNA positive nuclei in six independent microscopic fields at $40 \times$ magnification were counted. Differences in the average number of PCNA positive nuclei between $\mathrm{NaCl}$ and rcHGF treated livers were analysed using Student's $t$ test and SPSS software. A $P$ value $<0.05$ was considered statistically significant. A normal distribution of the data and homogeneity of variances were confirmed by Kolmogorov-Smirnov and Levene's tests.

\section{Results}

\section{Expression and partial purification of rcHGF}

Three days after infecting High-5 cells with recombinant baculovirus, rcHGF levels in the supernatant were 10 $20 \mathrm{mg} / \mathrm{L}$. The rcHGF was subsequently purified using a heparin-sepharose column. Protein-containing fractions that were eluted from the column with $0.7-1.2 \mathrm{M} \mathrm{NaCl}$ and a conduction of $50-70 \mathrm{~ms} / \mathrm{cm}$ were collected and analysed using silver staining (Fig. 1A) and Western blotting (Fig. 1B). Densitometric analysis of the silver staining showed that the purity of reHGF was $>85 \%$. As shown with Western blotting, HGF immunoreactive bands were seen at $82 \mathrm{kDa}$. After purification, rcHGF was diluted in $0.2 \mathrm{M} \mathrm{NaCl}$ in a stock concentration of $0.5 \mathrm{mg} / \mathrm{mL}$ and stored in aliquots at $-20{ }^{\circ} \mathrm{C}$. 


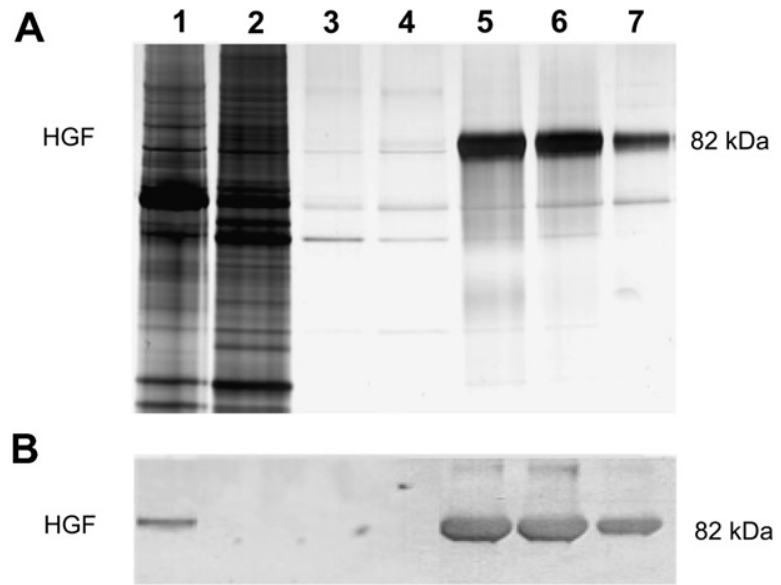

Fig. 1. Protein fractions collected during heparin sepharose purification of rcHGF. (A) The detection of the total amount of proteins by means of silver staining. (B) The detection of HGF specific bands by means of Western blot analysis. Lane 1: rcHGF after gamma irradiation, lane 2: rcHGF flow through, lane 3-7: rcHGF fractions eluted with 0.5 (lane 3), 0.6 (lane 4), 0.7 (lane 5), 1.0 (lane 6), and 1.2 (lane 7) $\mathrm{M} \mathrm{NaCl}$. As shown in (b), rcHGF was present in the fractions eluted from 0.7 to $1.2 \mathrm{M} \mathrm{NaCl}$.

\section{In vitro activity of $r c H G F$}

Both rcHGF and rhHGF stimulated cell growth of BDE cells in a similar dose-dependent manner. Cell growth started at a concentration of $11 \mathrm{ng} / \mathrm{mL}$ HGF, and maximum proliferation activity was seen at $100 \mathrm{ng} / \mathrm{mL}$ HGF (Fig. 2). As described by Tajima et al. (1992), HGF did not stimulate cell growth in MDCK cells.

rcHGF and rhHGF induced cell scattering of BDE cells and MDCK cells at a concentration of $10 \mathrm{ng} / \mathrm{mL}$ and $100 \mathrm{ng} / \mathrm{mL}$ HGF. Cells were considered to scatter when they lost cell-cell contact and obtained a more fibroblastic appearance, as described in previous studies (Balkovetz, 1998; Mori et al., 2004). Representative examples of rcHGF and rhHGF induced cell scattering are shown for MDCK and BDE cells in Fig. 3.

Western blot analysis was used to visualise the phosphorylation and the total amount of c-MET, PKB, and

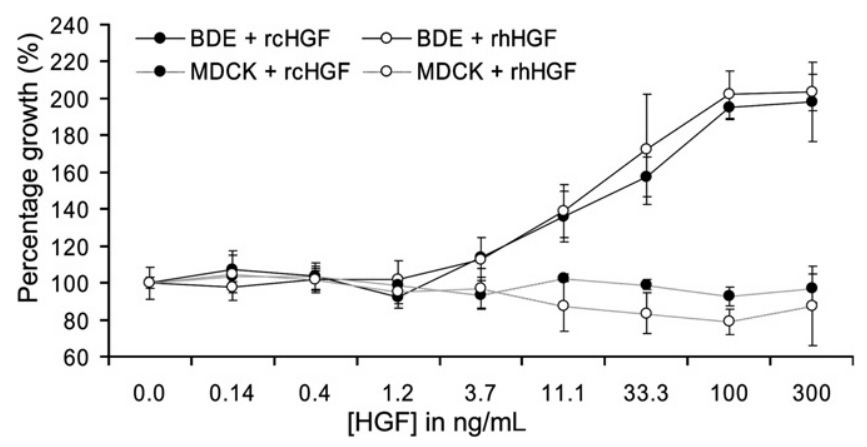

Fig. 2. In vitro mitogenic effect of reHGF and rhHGF on BDE and MDCK cells. Cells were grown in a 96-well culture plates in the presence of $0-100 \mathrm{ng} / \mathrm{mL} \mathrm{rcHGF}$ or rhHGF. After a 24 -h culture period, cell growth was measured by using the MTT proliferation assay. Results are presented as means $\pm \mathrm{SD}$. HGF induced cell growth in BDE cells in a dose-dependent manner. HGF did not induce cell growth in MDCK cells.
ERK1/2 in MDCK and BDE cells after treatment with 0, $1.5,15$, and $150 \mathrm{ng} / \mathrm{mL}$ rcHGF. Fig. 4 depicts the immunoreactive bands and the calculated ratios of the ODs of the phosphorylated protein towards the OD of the total protein. In BDE and MDCK cells, rcHGF induced c-MET phosphorylation (Y1230, Y1234, Y1235) and PKB (T308) phosphorylation in a dose dependent manner. The phosphorylation of PKB (T308) and ERK1/2 (T202/Y204) occurred in the presence of $15 \mathrm{ng} / \mathrm{mL}$ rcHGF in BDE cells, and in the presence of $1.5 \mathrm{ng} / \mathrm{mL} \mathrm{rcHGF}$ in MDCK cells. ERK1/2 phosphorylation did not occur in a dose dependent manner. The total amount of c-MET, PKB, or ERK1/2 proteins did not change when BDE and MDCK were treated with rcHGF. Western blotting against betaactin $(40 \mathrm{kDa})$ confirmed an equal amount of protein loading on the gel (data not shown).

\section{In vivo activity of rcHGF: (gross) pathology and organ weights}

No macroscopic abnormalities were found at necropsy 1 week after phx in any of the dogs that received rcHGF or $\mathrm{NaCl}$. No differences were found in organ weight/bodyweight ratio between the two groups for the liver (average ratio $\pm \mathrm{SD}$; rcHGF: $0.292 \pm 0.05 ; \mathrm{NaCl}: 0.316 \pm 0.05$ ), kidneys (average ratio $\pm \mathrm{SD}$; HGF: $0.051 \pm 0.01, \mathrm{NaCl}$ : $0.053 \pm 0.01$ ), heart (average ratio $\pm \mathrm{SD}$; HGF: $0.079 \pm 0.01, \mathrm{NaCl}: 0.071 \pm 0.03$ ), or spleen (average ratio $\pm \mathrm{SD}$; HGF: $0.084 \pm 0.02$; $\mathrm{NaCl}: 0.084 \pm 0.01$ ). Histopathological assessment of $\mathrm{H} \& \mathrm{E}$ stained slides indicated a normal architecture of the liver without any sign of hypertrophy, hyperplasia, or severe apoptosis at all time points measured.

In vivo activity of rcHGF: Western blot analysis of c-MET, $P K B$, and ERK1/2

Western blot analysis was used to visualise the phosphorylation and the total amount of c-MET (Fig. 5A), PKB (Fig. 5B), ERK1/2 (Fig. 5C), and PCNA (Fig. 5D) in pooled biopsies of $\mathrm{NaCl}$ and $\mathrm{HGF}$ treated livers at 0 , $2,3,4,5$, and 7 days after phx. The ODs of the immunoreactive bands were measured and corrected with the ODs of the non-phosphorylated protein, or beta-actin. The treatment of rcHGF increased the phosphorylation of c-MET (Y1230, Y1234, Y1235) at days 3, 4, and 5 after phx, the phosphorylation of PKB (T308) at days 2, 3, 4, and 5 after phx, and the phosphorylation of ERK1/2 (T202/Y204) at 4 , and 5 days after phx. The amount of the cell cycle protein PCNA was higher in rcHGF treated livers at days 3, and 5 after phx, and higher in the $\mathrm{NaCl}$ treated livers at 2 days after phx.

Immunohistochemistry confirmed a difference in the average amount of PCNA positive cells in HGF treated livers at 5 days after phx (Fig. 6), however no differences were found between $\mathrm{HGF}$ and $\mathrm{NaCl}$ treated dogs at days $0,2,3$, 4 , and 7. 

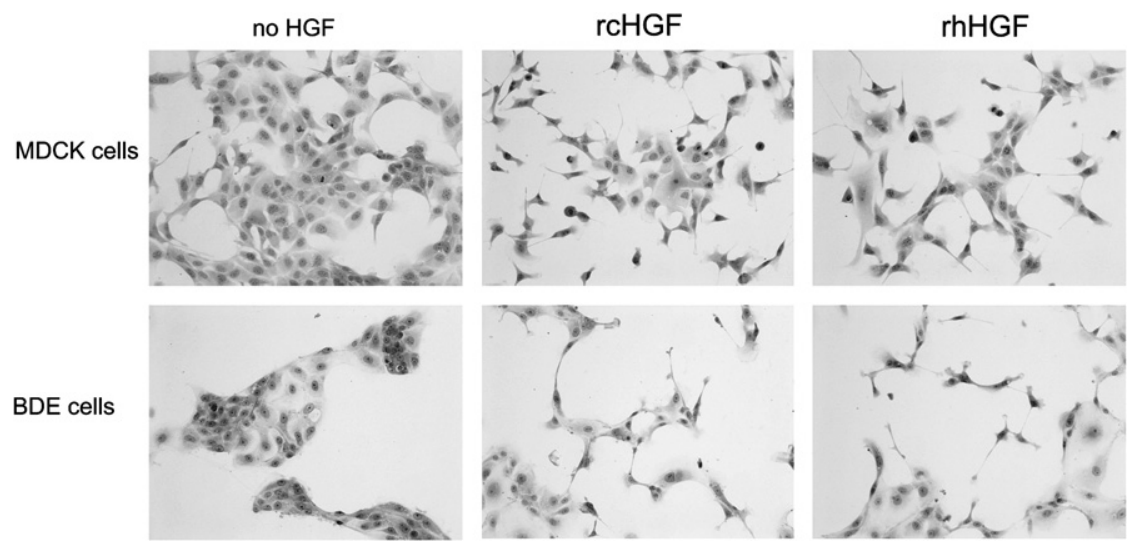

Fig. 3. In vitro motogenic effect of rcHGF or rhHGF on MDCK and BDE cells. Cells were grown in an 8-well chamber with or without $100 \mathrm{ng} / \mathrm{mL}$ rcHGF or rhHGF. After a 10-h culture period, cells were fixed in Boonfix for 5 min and stained with haematoxylin for 1 min. $20 \times$ magnification.
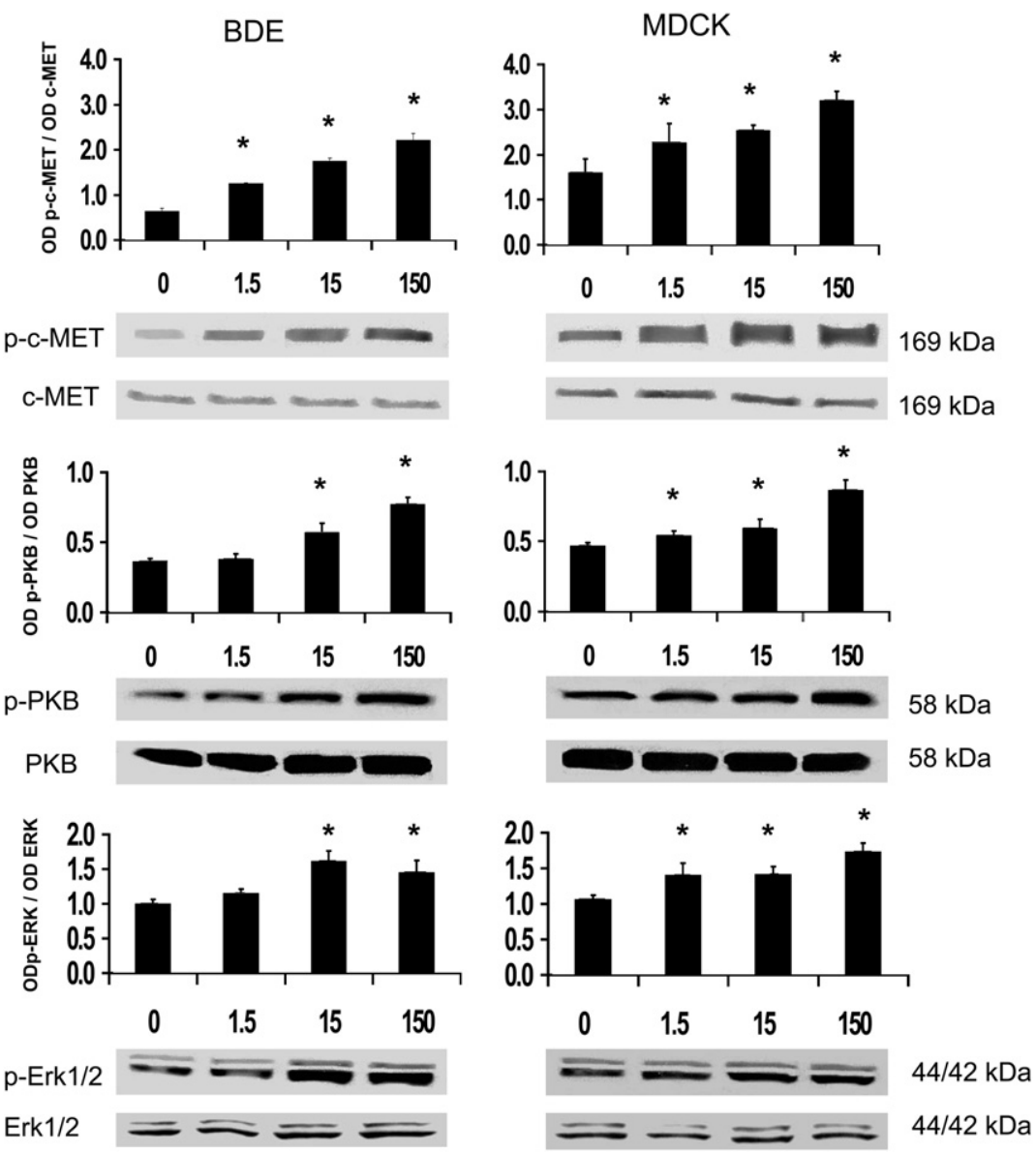

Fig. 4. Western blot analysis of phosphorylated and non-phosphorylated c-MET, PKB and ERK1/2, induced by $0,1.5,15$, or $150 \mathrm{ng} / \mathrm{mL} \mathrm{rcHGF}$ in BDE and MDCK cells. Optical densities (OD) of immunoreactive bands were measured in triplicate and presented as means \pm SD. Differences in means were considered significant when $P<0.05(*)$.

In vivo activity of rcHGF: Western blot analysis of caspase-3

Immunoreactive bands were found for inactive caspase$3(34 \mathrm{kDa})$ and two cleaved (activated) caspase- 3 subunits (20 and $18 \mathrm{kDa}$ ) in the individual samples at day 7 after phx (Fig. 7A). The ODs of the immunoreactive bands were measured and normalised with the ODs of beta-actin (Fig. 7B). When compared to $\mathrm{NaCl}$ treated livers, HGF treated livers showed similar levels of inactive caspase-3, and lower levels of the two cleaved subunits of caspase- 3 at 7 days after phx. 
A

A $25 \square \mathrm{NaCl} \square$ HGF
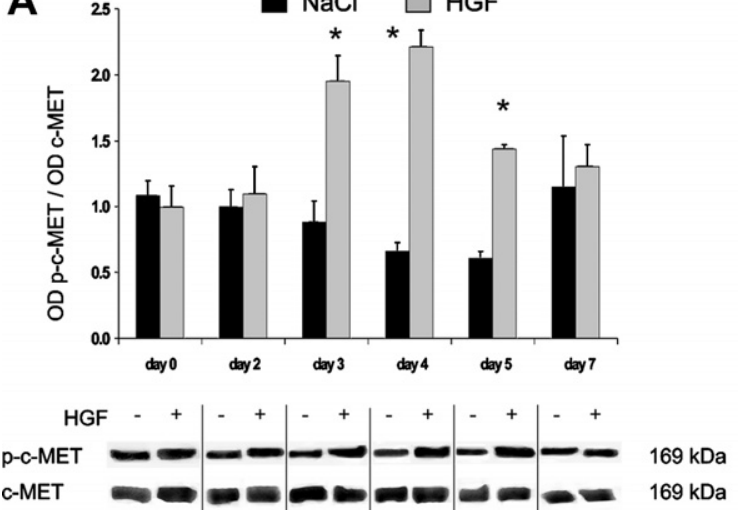

C

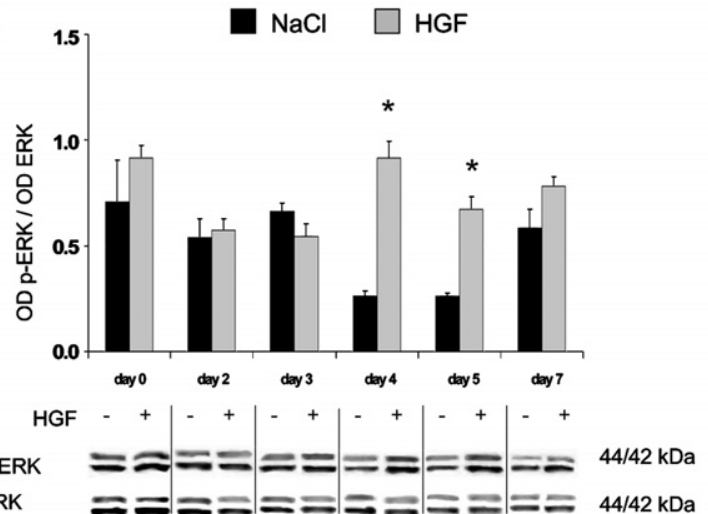

B
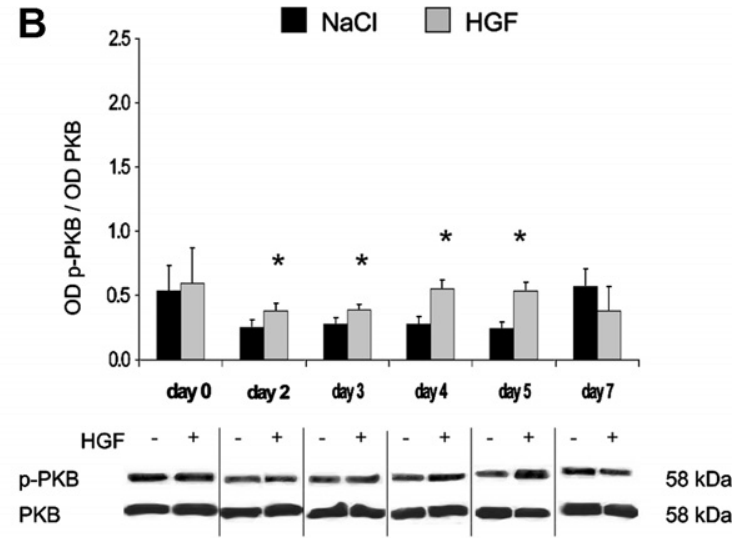

D

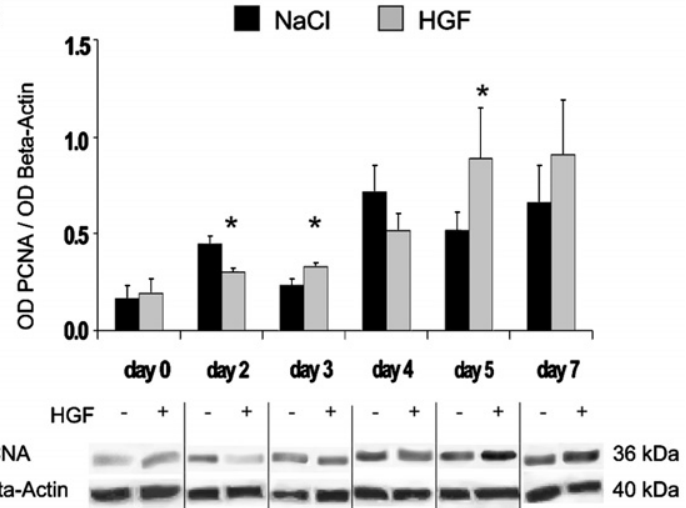

Fig. 5. Western blot analysis on pooled liver biopsies of $\mathrm{NaCl}(n=6)$, or $\mathrm{HGF}(n=6)$ treated livers at $0,2,3,5$, and 7 days after phx. Immunoreactive bands were detected for (A) c-MET, (B) PKB, (C) ERK1/2, (D) PCNA, and beta-actin. Optical densities (OD) of the immunoreactive bands were measured in triplicate and presented as means with SD. Differences in means were considered significant when $P<0.05(*)$.

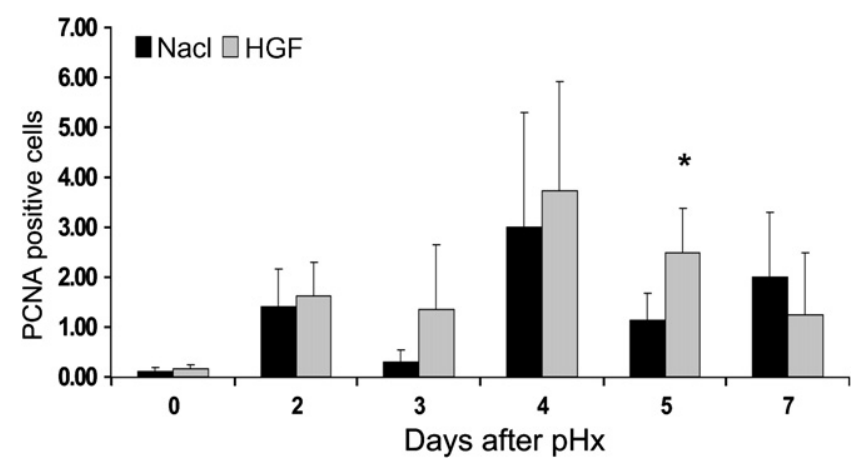

Fig. 6. Immunohistochemistry with a PCNA specific antibody on biopsies of $\mathrm{NaCl}(n=6)$, or $\mathrm{HGF}(n=6)$ treated livers at $0,2,3,4,5$, and 7 days after phx. The figure presents the average amount of PCNA positive nuclei in six different microscopic fields at $40 \times$ magnification with SD. Differences were considered significant when $P<0.05(*)$.

\section{Discussion}

HGF is considered the most important factor for the development and regeneration of the liver and the use of HGF may potentially be useful to stimulate liver regeneration in currently untreatable fatal liver diseases (Kosai et al., 1999; Ueki et al., 1999). Despite the discovery of HGF more than 20 years ago, the therapeutic use has never
A

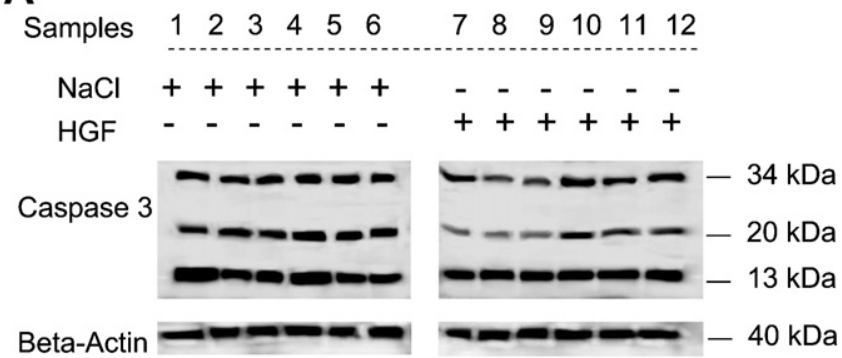

B

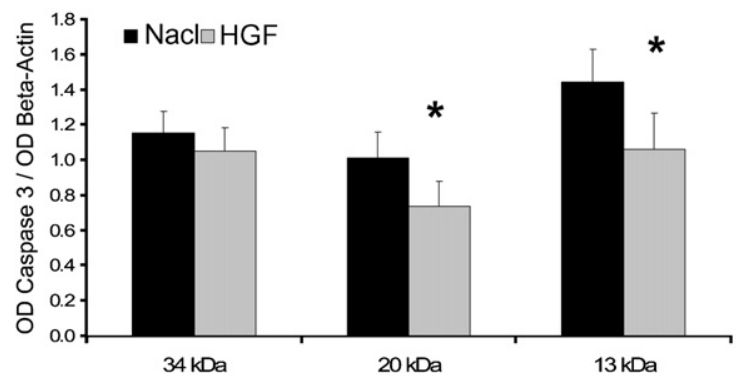

Fig. 7. (A) Western blot analysis for inactive ( $34 \mathrm{kDa})$ caspase- 3 , two active caspase- 3 subunits $(20$ and $13 \mathrm{kDa})$, and beta-actin $(40 \mathrm{kDa})$ on liver biopsies of $\mathrm{NaCl}(n=6)$, or HGF $(n=6)$ treated livers at 7 days after phx. (B) The optical density (OD) of the caspase- 3 immunoreactive bands were corrected with the OD of beta-actin and presented as a mean ratio $\pm \mathrm{SD}$ for $\mathrm{NaCl}(n=6)$ and $\mathrm{HGF}(n=6)$ samples. Differences in means were considered significant when $P<0.05(*)$. 
been evaluated in naturally occurring liver diseases. As a step toward performing first clinical studies in dogs, biologically active rcHGF was produced using a baculoviral expression system in High-5 cells.

The described production and purification strategy produces sufficient biological active reHGF to start clinical trials in dogs. However, the rcHGF product obtained should be further purified before the studies start. The generation of rcHGF was higher than the previously reported production of rhHGF using insect (Wang et al., 2000; Yee et al., 1993) or mammalian cells (Nakamura et al., 1989). The use of other production systems, for instance the yeast Pichia pastoris (Liu et al., 2005) may yield even higher quantities of $>500 \mathrm{mg} / \mathrm{L}$ recombinant HGF. When the effects of post-transcriptional modifications such as glycosylation (Fukuta et al., 2005) are fully known in vivo, the use of other production systems, such as non-eukaryotic cells may offer a tool for mass production of rcHGF.

In the present study, rcHGF increased the phosphorylation of c-MET, PKB and ERK1/2 in vitro and in vivo. The biological activities of HGF are mediated by the phosphorylation of tyrosine residues of the c-MET receptor. Following HGF-induced phosphorylation, c-MET binds and phosphorylates several intracellular signal transduction molecules that are important for the regeneration of the liver, such as PKB and ERK1/2, one of the Ras-mitogenactivated protein (MAP) kinase cascade (Borowiak et al., 2004). In general, PKB plays a major role in cell viability, while MAP kinases are important in the regulation of cell growth, motility and differentiation (Nakagami et al., 2001). On the other hand, altered expression of receptor tyrosine kinases has been shown to play a role in a variety of malignancies (Maulik et al., 2002). Regarding the sustained phosphorylation c-MET and downstream pathways of c-MET in the present study, the potential of reHGF to induce malignancies needs to be evaluated before clinical application.

rcHGF moderately increased the amount of PCNA positive cells but no increase in liver weight was seen at 7 days after phx. This may be explained by the relatively low amount of $\mathrm{rcHGF}(10 \mu \mathrm{g} / \mathrm{kg} / \mathrm{day})$ that was given when compared to similar experiments in rats and mice (Ishiki et al., 1992; Webber et al., 1994). In the rodent models, the amount of HGF that is used is highly variable and ranges between $30 \mu \mathrm{g} / \mathrm{kg} / \mathrm{day}$ to $5 \mathrm{mg} / \mathrm{kg} /$ day (Ido et al., 2004; Ishiki et al., 1992; Kosai et al., 1999; Matsuda et al., 1997; Sato et al., 2000; Webber et al., 1994). Considering that the degree of HGF activity is dose dependent, a stronger effect of rcHGF on liver cell proliferation might be expected with an increased amount of HGF. However, Kobayashi et al. (1996) showed that a very low dose of $0.5 \mu \mathrm{g} / \mathrm{kg} / \mathrm{day}$ of HGF was sufficient to increase liver weight in dogs at 3 days following phx, so another explanation may be that differences in liver weight could have occurred in the present study earlier than 7 days. This is corroborated by the increased ERK1/2 phosphorylation at days 4 and 5 and an increased amount of PCNA positive cells at day 5, while no differences were found at day 7 .

HGF may prevent apoptosis by transcriptionally inducing the Bcl2 family member Mcl-1 and FLIPs through the PKB pathway (Moumen et al., 2007; Xiao et al., 2001). Furthermore, altered caspase-3 levels during liver regeneration were suggested to play a role in remodelling the regenerating liver (Fan et al., 1998). In the present study, the administration of $\mathrm{rcHGF}$ decreased active caspase-3 levels at 7 days after phx. Additional studies are required to examine the exact role and contribution of caspase-3 during liver regeneration.

Clinical studies using rcHGF in veterinary medicine in dogs are feasible because clinical and clinicopathological examination, diagnostic imaging (ultrasonography, scintigraphy, CT scanning, etc.), and liver biopsies are routinely available techniques in dogs. Furthermore, a world consensus statement was recently reported, addressing clinical and histopathological diagnostic criteria of canine liver diseases such as fulminating, acute, and chronic hepatitis, as well as cirrhosis (WSAVA, 2006). This consensus provided researchers with a well defined, uniform terminology and diagnostic criteria that will allow comparison of canine diseases with similar human liver disorders and results between different studies.

\section{Conclusions}

Both in vitro and in vivo studies showed biologically active rcHGF and the High-5 expression system produced sufficient amounts of reHGF to be used in future clinical studies of naturally occurring canine liver diseases.

\section{Acknowledgements}

The authors wish to thank the employees at the GDLAnimal Laboratory (Utrecht University) for their thorough work and their critical input before and during the animal experiments.

\section{References}

Balkovetz, D.F., 1998. Hepatocyte growth factor and Madin-Darby canine kidney cells: in vitro models of epithelial cell movement and morphogenesis. Microscopy Research and Technique 43, 456463.

Borowiak, M., Garratt, A.N., Wustefeld, T., Strehle, M., Trautwein, C., Birchmeier, C., 2004. Met provides essential signals for liver regeneration. Proceedings of the National Academy of Sciences of the United States of America 101, 10608-10613.

Bottaro, D.P., Rubin, J.S., Faletto, D.L., Chan, A.M., Kmiecik, T.E., Vande Woude, G.F., et al., 1991. Identification of the hepatocyte growth factor receptor as the c-MET proto-oncogene product. Science 251, 802-804.

Carmichael, J., DeGraff, W.G., Gazdar, A.F., Minna, J.D., Mitchell, J.B., 1987. Evaluation of a tetrazolium-based semiautomated colorimetric assay: assessment of chemosensitivity testing. Cancer Research 47, 936-942.

Fan, G., Kren, B.T., Steer, C.J., 1998. Regulation of apoptosis-associated genes in the regenerating liver. Seminars in Liver Disease 18, 123-140. 
Fukuta, K., Matsumoto, K., Nakamura, T., 2005. Multiple biologica responses are induced by glycosylation-deficient hepatocyte growth factor. Biochemical Journal 388, 555-562.

Funakoshi, H., Nakamura, T., 2003. Hepatocyte growth factor: from diagnosis to clinical applications. Clinica Chimica Acta 327, 1-23.

Ido, A., Moriuchi, A., Kim, I., Numata, M., Nagata-Tsubouchi, Y., Hasuike, S., et al., 2004. Pharmacokinetic study of recombinant human hepatocyte growth factor administered in a bolus intravenously or via portal vein. Hepatology Research 30, 175-181.

Ishiki, Y., Ohnishi, H., Muto, Y., Matsumoto, K., Nakamura, T., 1992. Direct evidence that hepatocyte growth factor is a hepatotrophic factor for liver regeneration and has a potent antihepatitis effect in vivo. Hepatology 16, 1227-1235.

Jin, H., Wyss, J.M., Yang, R., Schwall, R., 2004. The therapeutic potential of hepatocyte growth factor for myocardial infarction and heart failure. Current Pharmaceutical Design 10, 2525-2533.

Kobayashi, Y., Hamanoue, M., Ueno, S., Aikou, T., Tanabe, G., Mitsue, S., et al., 1996. Induction of hepatocyte growth by intraportal infusion of HGF into beagle dogs. Biochemical Biophysical Research Communications 220, 7-12.

Kosai, K., Matsumoto, K., Funakoshi, H., Nakamura, T., 1999. Hepatocyte growth factor prevents endotoxin-induced lethal hepatic failure in mice. Hepatology 30, 151-159.

Kost, T.A., Condreay, J.P., Jarvis, D.L., 2005. Baculovirus as versatile vectors for protein expression in insect and mammalian cells. Nature Biotechnology 23, 567-575.

Liu, Y., 2004. Hepatocyte growth factor in kidney fibrosis: therapeutic potential and mechanisms of action. American Journal of PhysiologyRenal Physiology 287, F7-F16.

Liu, Z.M., Zhao, H.L., Xue, C., Deng, B.B., Zhang, W., Xiong, X.H., et al., 2005. Secretory expression and characterization of a recombinant-deleted variant of human hepatocyte growth factor in Pichia pastoris. World Journal of Gastroenterology 11, 7097-7103.

Ma, P.C., Maulik, G., Christensen, J., Salgia, R., 2003. c-Met: structure, functions and potential for therapeutic inhibition. Cancer Metastasis Reviews 22, 309-325.

Maina, F., Klein, R., 1999. Hepatocyte growth factor, a versatile signal for developing neurons. Nature Neuroscience 2, 213-217.

Matsuda, Y., Matsumoto, K., Yamada, A., Ichida, T., Asakura, H., Komoriya, Y., et al., 1997. Preventive and therapeutic effects in rats of hepatocyte growth factor infusion on liver fibrosis/cirrhosis. Hepatology $26,81-89$.

Matsumoto, K., Nakamura, T., 1992. Hepatocyte growth factor: molecular structure, roles in liver regeneration, and other biological functions. Critical Reviews in Oncogenesis 3, 27-54.

Maulik, G., Shrikhande, A., Kijima, T., Ma, P.C., Morrison, P.T., Salgia, R., 2002. Role of the hepatocyte growth factor receptor, c-Met, in oncogenesis and potential for therapeutic inhibition. Cytokine \& Growth Factor Reviews 13, 41-59.

Miyake, M., Saze, K., Yaguchi, T., Wang, J., Suzuta, Y., Haga, Y., et al., 2003. Canine hepatocyte growth factor: molecular cloning and characterization of the recombinant protein. Veterinary Immunology and Immunopathology 95, 135-143.

Mori, H., Hirabayashi, S., Shirasawa, M., Sugimura, H., Hata, Y., 2004. JAM4 enhances hepatocyte growth factor-mediated branching and scattering of Madin-Darby canine kidney cells. Genes Cells 9, 811-819.

Moumen, A., Ieraci, A., Patane, S., Sole, C., Comella, J.X., Dono, R., et al., 2007. Met signals hepatocyte survival by preventing Fastriggered FLIP degradation in a PI3k-Akt-dependent manner. Hepatology 45, 1210-1217.

Nakagami, H., Morishita, R., Yamamoto, K., Taniyama, Y., Aoki, M., Matsumoto, K., et al., 2001. Mitogenic and antiapoptotic actions of hepatocyte growth factor through ERK, STAT3, and AKT in endothelial cells. Hypertension 37, 581-586.
Nakamura, T., Nishizawa, T., Hagiya, M., Seki, T., Shimonishi, M., Sugimura, A., et al., 1989. Molecular cloning and expression of human hepatocyte growth factor. Nature 342, 440-443.

Oda, D., Lee, S.P., Hayashi, A., 1991. Long-term culture and partial characterization of dog gallbladder epithelial cells. Laboratory Investigation $64,682-692$.

Rothuizen, J., 1999. Diseases of the Liver and Biliary Tract. Saunders, London.

Rothuizen, J., Meyer, H.P., 2000. History, Physical Examination, and Clinical Signs of Liver Disease. Saunders, Philadelphia.

Sato, M., Kakubari, M., Kawamura, M., Sugimoto, J., Matsumoto, K., Ishii, T., 2000. The decrease in total collagen fibers in the liver by hepatocyte growth factor after formation of cirrhosis induced by thioacetamide. Biochemical Pharmacology 59, 681-690.

Schmidt, C., Bladt, F., Goedecke, S., Brinkmann, V., Zschiesche, W., Sharpe, M., et al., 1995. Scatter factor/hepatocyte growth factor is essential for liver development. Nature 373, 699-702.

Shiota, G., Okano, J., Kawasaki, H., Kawamoto, T., Nakamura, T., 1995. Serum hepatocyte growth factor levels in liver diseases: clinical implications. Hepatology 21, 106-112.

Spee, B., Arends, B., van den Ingh, T.S.G.A.M., Brinkhof, B., Nederbragt, H., Ijzer, J., et al., 2006. Transforming growth factor beta-1 signaling in canine hepatic diseases: new models for human fibrotic liver pathologies. Liver International 26, 716-725.

Spee, B., Penning, L.C., van den Ingh, T.S., Arends, B., Ijzer, J., van Sluijs, F.J., et al., 2005. Regenerative and fibrotic pathways in canine hepatic portosystemic shunt and portal vein hypoplasia, new models for clinical hepatocyte growth factor treatment. Comparative Hepatology $4,7$.

Stella, M.C., Comoglio, P.M., 1999. HGF: a multifunctional growth factor controlling cell scattering. International Journal of Biochemistry \& Cell Biology 31, 1357-1362.

Stoker, M., Perryman, M., 1985. An epithelial scatter factor released by embryo fibroblasts. Journal of Cell Science 77, 209-223.

Tajima, H., Matsumoto, K., Nakamura, T., 1992. Regulation of cell growth and motility by hepatocyte growth factor and receptor expression in various cell species. Experimental Cell Research 202, 423-431.

Ueki, T., Kaneda, Y., Tsutsui, H., Nakanishi, K., Sawa, Y., Morishita, R., et al., 1999. Hepatocyte growth factor gene therapy of liver cirrhosis in rats. Nature Medicine 5, 226-230.

Wang, M.Y., Yang, Y.H., Lee, H.S., Lai, S.Y., 2000. Production of functional hepatocyte growth factor (HGF) in insect cells infected with an HGF-recombinant baculovirus in a serum-free medium. Biotechnology Progress 16, 146-151.

Webber, E.M., Godowski, P.J., Fausto, N., 1994. In vivo response of hepatocytes to growth factors requires an initial priming stimulus. Hepatology 19, 489-497.

WSAVA, L.S.G., 2006. Standards for Clinical and Histological Diagnosis of Canine and Feline Liver Diseases. Saunders/Elsevier, London.

Xiao, G.H., Jeffers, M., Bellacosa, A., Mitsuuchi, Y., Vande Woude, G.F., Testa, J.R., 2001. Anti-apoptotic signaling by hepatocyte growth factor/Met via the phosphatidylinositol 3-kinase/Akt and mitogen-activated protein kinase pathways. Proceedings of the National Academy of Sciences of the Unites States of America 98, 247-252.

Yasuda, H., Imai, E., Shiota, A., Fujise, N., Morinaga, T., Higashio, K., 1996. Antifibrogenic effect of a deletion variant of hepatocyte growth factor on liver fibrosis in rats. Hepatology 24, 636-642.

Yee, C.J., DeFrances, M.C., Bell, A., Bowen, W., Petersen, B., Michalopoulos, G.K., et al., 1993. Expression and characterization of biologically active human hepatocyte growth factor (HGF) by insect cells infected with HGF-recombinant baculovirus. Biochemistry 32, 7922-7931. 